\title{
Is High Quality Breast Imaging and Diagnosis Possible in a Decentralized System? The QuaMaDi Project
}

\author{
Ingrid Schreer ${ }^{a}$ Alexander Katalinic ${ }^{b}$ \\ ${ }^{a}$ Mammazentrum Universitätsklinik Schleswig-Holstein, Campus Kiel, \\ bInstitut für Krebsepidemiologie, Universität zu Lübeck, Germany
}

\section{Key Words}

Breast cancer - Diagnosis - Mammography .

Assessment · Quality assurance

\section{Summary}

A pilot project by the KVSH (Kassenärztliche Vereinigung Schleswig-Holstein), health insurance companies, gynecologists and radiologists in private practice together with the Breast Center, University Schleswig-Holstein, Campus Kiel and the Institute for Cancer Epidemiology, Campus Lübeck was started in May 2001 and finished in December 2005. 59,514 women with breast problems were diagnosed. A multidisciplinary comprehensive quality management following the EU Guidelines for Mammography Screening was implemented in combination with the national Early Breast Cancer Detection Guideline. Both guidelines afforded new structures and processes which had to be integrated into the existing health care system, most importantly complete documentation and outcome evaluation. This encompassed quality assurance of physical technical aspects, radiographical training and education, specialized training for radiologists, consecutive independent double readings, continuous multidisciplinary training and, in the case of dissent and BI-RADS ${ }^{\text {TM }} 4$ and 5 lesions, expert third readings and standardized assessment. The whole diagnostic chain had to be documented for evaluation and benchmarking purposes. With the use of quality indicators, the amelioration effects became measurable. Breast cancer incidence and stage distribution were determined. A total of 102,744 diagnostic processes were indicated, resulting in $24,470(23.8 \%)$ third readings by the reference center. A recommendation for further assessment was initiated. 1,056 invasive/non-invasive breast cancer cases $(10.3 / 1,000$ examinations) were diagnosed. In comparison with the whole of Schleswig-Holstein, a much more favorable tumor stage distribution was achieved: $62.6 \%$ in situ and T1 vs. $48.6 \%$ in the remaining Schleswig-Holstein. These results indicate that comprehensive quality assurance measures are not only absolutely essential in the area of so-called curative medical care, but that they can also be effectively implemented in our decentralized medical care system.
Schlüsselwörter

Brustkrebs · Diagnostik · Mammographie · Abklärung · Qualitätssicherung

\section{Zusammenfassung}

In einem gemeinsamen von KVSH (Kassenärztliche Vereinigung Schleswig-Holstein), Krankenkassen, niedergelassenen Gynäkologen und Radiologen, dem Mammazentrum des Universitätsklinikums Schleswig-Holstein, Campus Kiel, sowie dem Institut für Krebsepidemiologie der Universität zu Lübeck getragenen Modellprojekt wurden von Mai 2001 bis Dezember 200559514 Frauen mit einer Indikation zur diagnostischen Mammographie untersucht. Es wurde ein multidisziplinäres Qualitätsmanagement auf der Basis der europäischen Mammographierichtlinien für Qualitätssicherung beim Mammographie-Screening sowie der Stufe-3-Leitlinie Brustkrebsfrüherkennung implementiert. Dadurch wurden neue Strukturen und Prozesse in das bisherige Versorgungssystem integriert und eine umfassende Dokumentation und Ergebnisevaluation durchgeführt. Die wesentlichen Instrumente waren neben der technisch-apparativen Qualitätssicherung und dem kontinuierlichen spezifischen Training der technischen Mitarbeiterinnen und der Radiodiagnostiker vor allem die konsekutive unabhängige Doppelbefundung, Expertendrittbefundung im Referenzzentrum bei Dissens bzw. Abklärungsbedarf, standardisierte Abklärung und vor allem umfassende Dokumentation, die Evaluation und Feedback möglich machte. Anhand von Qualitätsindikatoren konnte die Qualitätsverbesserung über die Zeit gemessen werden, es wurde die Mammakarzinominzidenz und Stadienverteilung ermittelt. 10274400 diagnostische Prozesse wurden veranlasst. Es ergab sich in $23,8 \%$ der Fälle (24 470) die Notwendigkeit der Drittbefundung im Referenzzentrum. Es wurde bei 6442 Patientinnen eine Empfehlung zur Abklärung gegeben. 1056 Mammakarzinome (10,3/1000 Untersuchungen) wurden diagnostiziert und zwar innerhalb des Projektes häufiger in günstigerer Stadienverteilung (in situ und T1-Tumore) mit $62,6 \%$ gegenüber $48,6 \%$ im restlichen Schleswig-Holstein. Dies zeigt, dass umfassende Qualitätssicherungsmaßnahmen im Bereich der so genannten kurativen Versorgung nicht nur dringend notwendig sondern auch innerhalb unseres dezentralen Versorgungssystems effektiv umsetzbar sind.

\begin{tabular}{|c|c|}
\hline KARGER & (c) 2007 S. Karger GmbH, Freiburg \\
\hline $\begin{array}{l}\text { Fax +49 } 7614520714 \\
\text { E-mail Information@Karger.de } \\
\text { www.karger.com }\end{array}$ & $\begin{array}{l}\text { Accessible online at: } \\
\text { www.karger.com/brc }\end{array}$ \\
\hline
\end{tabular}

Prof. Dr. med. Ingrid Schreer 


\section{Introduction}

Mammography screening allows to reduce breast cancer mortality [1-3]. National screening programs, so-called service screening, which will often have evolved from randomized controlled screening trials, usually exist in countries with a centralized health service (e.g. Sweden, Norway, Finland, The Netherlands, Great Britain). In Europe, it is agreed that service screening should be performed following the European Guidelines for Mammography Screening and Diagnosis $[4,5]$. That is, strict requirements have to be fulfilled concerning quality of structure, process and outcome. So far, only 11 of the 25 European states offer nationwide mammography screening programs which more or less follow the European guidelines. Among decentralized systems 'early diagnosis' may be offered as is the case in the United States. On the one hand, establishment of such a program for quality assurance and its logistics requires to fight numerous barriers. On the other hand, without an adequate quality assurance program quality may be insufficient and variable. Therefore, for Germany, the decision was passed to establish a nationwide centralized breast screening program. Nationwide availability of breast screening is anticipated for the end of 2007. Thus, for the first time in our country quality assured screening mammography provided in a structured program will be offered to all women aged 50-69 for free. It is hoped that this will reduce the variability of the service due to opportunistic screening.

The introduction of breast screening corresponds to the social obligation to also offer early detection to women who have so far not been aware of the possibilities of early detection or who could not afford it. However, it has to be considered that only the target population (women aged 50-69) will profit from a structured screening program, whereas women outside this age group, symptomatic women, women at risk, women with previous breast cancer or after histopathologic diagnosis of borderline lesions (risk indicators) may not profit, since they are entitled to undergo the usual diagnostic breast imaging with lower quality standards. This concerns a very important problem: Considering the age distribution of breast cancer, only $45 \%$ of all breast cancers are expected to occur in the target population [6], whereas $55 \%$ have to be diagnosed outside mammography screening by the traditional mammography service.

Schleswig-Holstein is the federal state in Germany with the highest incidence of breast cancer. Thus, health politics were faced with a special demand for improved breast diagnosis and service. Thanks to a well functioning cancer registry with complete documentation of breast cancers, epidemiologic data before the start of a new program were well known. This is an important prerequisite for the establishment and monitoring of a quality-assured program that was initiated to allow a reliable and early diagnosis of breast cancer.

QuaMaDi (Quality-assured MammaDiagnostics) started in July 2001 and worked as a pilot project for a period of 5 years
[7]. Approximately 325,000 women $(293,000$ women above the age of 20) live in the pilot region which is located in the federal state of Schleswig-Holstein. Almost all gynecologists $(\mathrm{n}=84)$ and radiologists $(\mathrm{n}=20)$ and one reference center took part in this region. Evaluation was performed by the Institute for Cancer Epidemiology in Lübeck. In the case of malignancy, this institute also requested and documented the exact staging data. The data concerning breast cancer incidence and tumor stages of the pilot region were compared to those of the remaining state of Schleswig-Holstein based on the existing data of the cancer registry. Statistical analysis was descriptive using absolute and relative frequencies for qualitative variables and mean values with standard deviation for quantitative variables.

The project was supported by several health insurance companies, the Kassenärztliche Vereinigung Schleswig-Holstein (KVSH), the Ministry for Social Affairs and Family of Schleswig-Holstein and the Deutsche Krebshilfe e.V. (German Cancer Aid).

\section{Quality Assurance in the Project}

\section{Structure of the Project}

QuaMaDi uses the existing structure of the decentralized Health System in Germany. That is, the participants of the project include gynecologists and radiologists in private practice, the KVSH and the health insurance companies, furthermore the Breast Center of the University Hospital of Schleswig-Holstein, Campus Kiel and the Institute for Cancer Epidemiology in Lübeck. Doctors can choose to participate. Participation is, however, regulated by written contract.

A committee composed of representatives of the gynecologists and radiologists in private practice, the KVSH, the health insurance companies and representatives of the University Campuses of Schleswig-Holstein meets at regular intervals to monitor the project and manage potential problems.

\section{Project Design}

The process quality algorithm of QuaMaDi is shown in figure 1. For patients, participation is voluntary. Participation starts by seeing a gynecologist for a breast problem. This follows the usual flow of patients in Germany. The gynecologist obtains the patient's individual history, performs a clinical examination and decides whether mammography is indicated. If this is the case, he informs the patient about the project and asks for written consent. He documents history and clinical data on a standardized form which is also forwarded to the radiologist. The patient can now choose a radiologist in the area of the project, who will perform the mammogram. The mammography report and diagnosis are documented on another stan- 


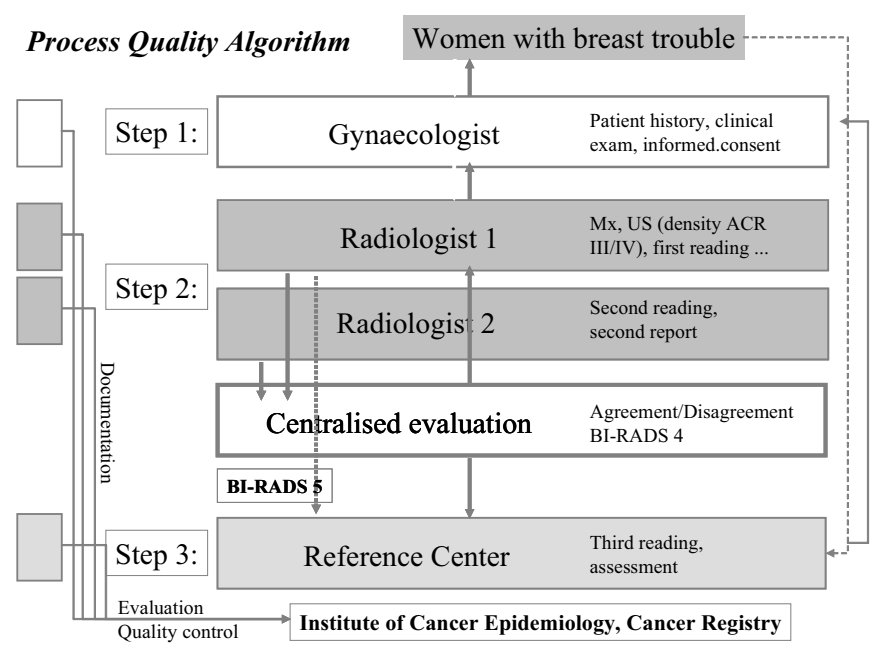

Fig. 1. Process quality algorithm of Quality-assured MammaDiagnostic (QuaMaDi).

dardized form using the BI-RADS-classification [8]. In the case of dense breast tissue (density class ACR III and IV), the patient is always additionally examined by ultrasound. All documented images go to a second reader who reads them independently and documents the results on the standardized form. First and second readings are compared centrally (by the KVSH), resulting in agreement or disagreement. In the case of disagreement and in cases with suspicion of malignancy (BIRADS IV), the first reader is informed and has to send all documented images to the Breast Center where a third reading takes place. In cases with highly suspicious findings, the second reader is circumvented to allow the fastest possible diagnosis and start of therapeutic measures.

The expert reading at the Breast Center may lead to the following results: Either a final diagnosis is possible based on all documented images or further assessment is needed. In the latter case, the patient's gynecologist receives a proposed date for the assessment exams, which he has to pass on to the patient. On the scheduled date, the patient is always reexamined clinically. Additional mammographic views and another ultrasound exam can be performed. If suspicion of malignancy is confirmed, a histological assessment is performed, mostly by sonographically guided biopsy or, if indicated, by vacuum-assisted stereotactic breast biopsy (e.g. in the case of microcalcifications). If a complex cyst is suspected, cytological assessment using fine needle aspiration is indicated. The results are documented using standardized forms of the breast center, since a comprehensive evaluation of the project is not possible without a complete and standardized documentation.

Between May 2001 and December 2005, 102,744 mammographic examinations were performed, supplemented by about $59,000(57.8 \%)$ ultrasound examinations. $7.4 \%$ of the mammograms were classified suspicious by the first or second radiologist, respectively. Disagreement (between BI-RADS $1 / 2$ vs. BI-RADS 3) occurred in

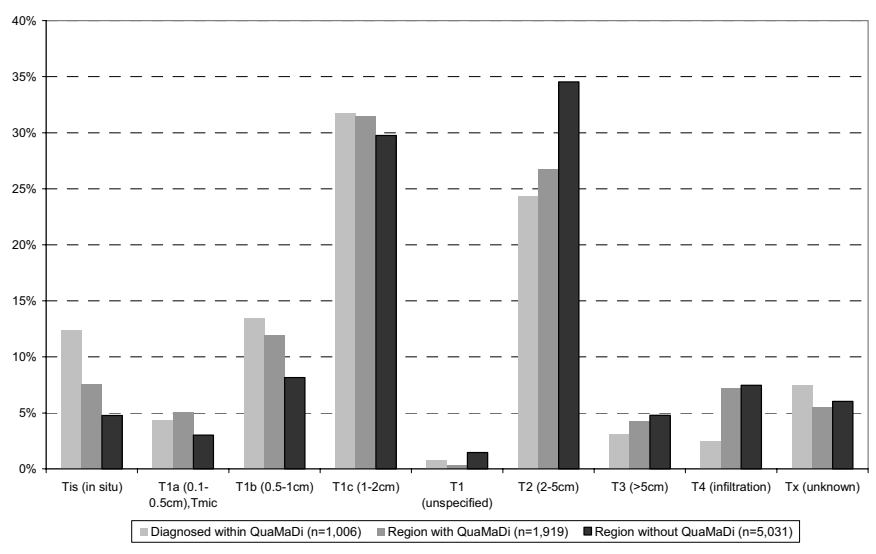

Fig. 2. Tumor stage distribution of QuaMaDi patients (2001-2004) and in regions with and without QuaMaDi (2001-2003).

16,463 cases $(16.4 \%)$. On average, there was a period of 3 days between the first and second examination. Further results can be found in the publications by Katalinic et al. [7, 9].

Altogether, 24,470 (23.8\%) cases had expert readings performed in the reference center, based on a BI-RADS 4 or BI-RADS 5 report of both readers or based on disagreement between the readers (BI-RADS $1 / 2$ vs. 3). Based on this centralized reading, further assessment was recommended in 6,442 cases of which 5,766 were carried out in the reference center. Mostly additional mammographic views (using different tube angulation, magnification, or spot compression) as well as ultrasound exams were performed. In 760 (13.2\%) cases, fine needle aspiration was indicated, which confirmed complex cysts in $68.3 \%$ and juvenile fibroadenoma in $10.5 \%$ of cases. 1,540 core needle or vacuum-assisted breast biopsies revealed 661 malignancies $(42.9 \%) ; 157$ breast cancers were diagnosed by open biopsy only. When adding 238 cases of breast cancer which were assessed and diagnosed outside the reference center, a total of 1,056 breast cancers were detected during the project period (10.3/1,000 assessments). Overall, the initial double reading showed a complete consensus in $61.4 \%$ of cases. When BI-RADS $1 / 2$ was grouped together with BI-RADS 3 versus BI-RADS 4 and 5 , a consensus was achieved in $78.1 \%$ of all double readings.

The documented indicators of quality were used for a process-related bench marking. Feedback of the quality indicators, which was provided every 3 months throughout the project, proved to be an excellent means for continuous quality improvement. For example, at the beginning of the project, the rate of recalls for further assessment first increased due to uncertainty of the readers. After an initial period, it dropped to a rate of $7 \%$ in 2003 and has reached a level of $4-5 \%$ at the end of 2005 . 


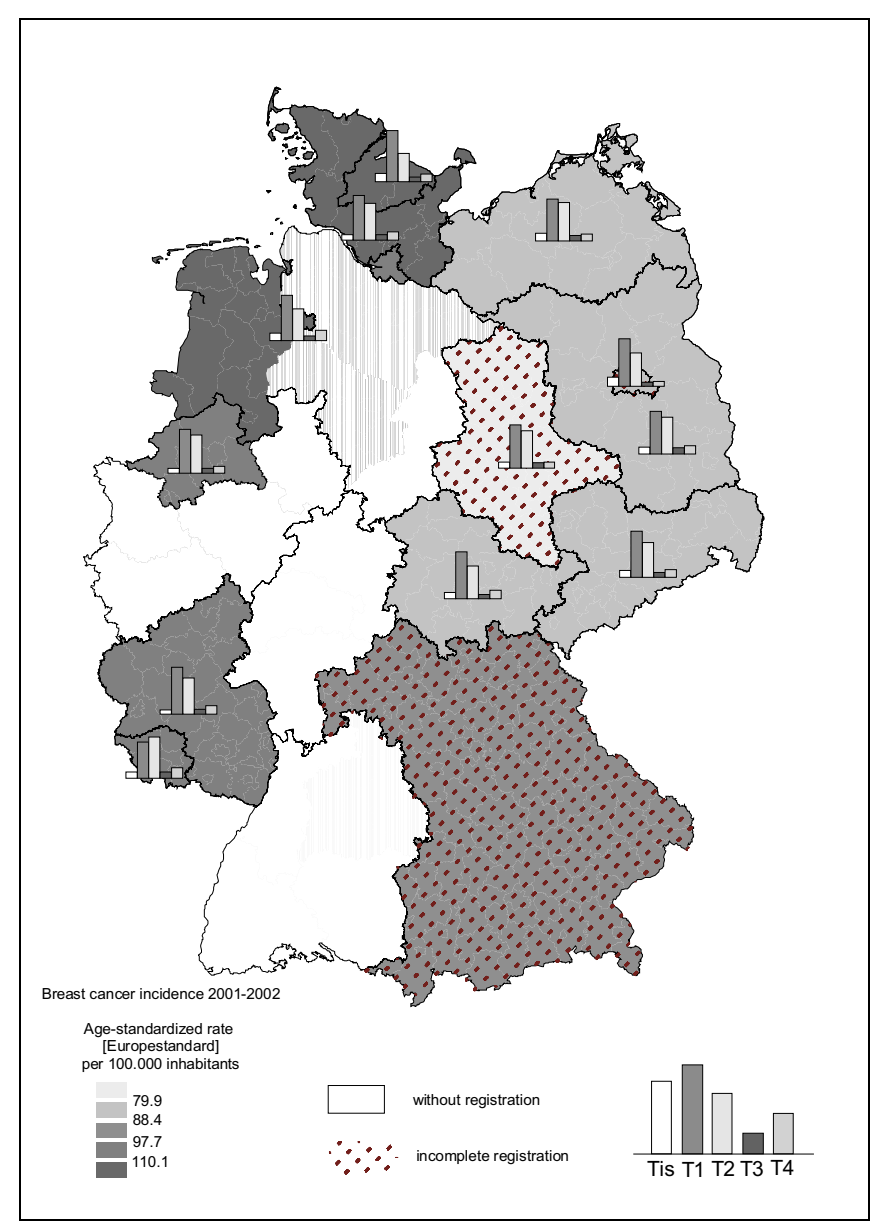

Fig. 3. Age-standardized breast cancer incidence and tumor stage in German counties (data sources: Krebs in Deutschland, 5th ed., GEKID and RKI (2006) and different annual reports of German cancer registers (2002/3), access: www.gekid.de).

In the pilot region, the age-standardized incidence of breast cancer increased by about $7.5 \%$, while it remained unchanged in the rest of Schleswig-Holstein. The stage distribution of the cancers diagnosed in the QuaMaDi patients or within the QuaMaDi region is shown in figure 2 as compared to the rest of Schleswig-Holstein. The comparison shows that in the QuaMaDi patients 62.6\% of all cancers were detected in situ or at a T1 stage, whereas this was the case in only $48.6 \%$ of the patients in the rest of Schleswig-Holstein.

Recently published data of the German cancer registers (fig. 3) underline the improvements which can potentially be achieved for symptomatic patients by a complete quality management including documentation and evaluation.

\section{Discussion}

Whereas the quality of service screening programs has been evaluated reasonably well [10-19], only few data exist concerning diagnostic mammography in both centrally organized health care systems and decentralized structures. This includes one publication from California (Breast Cancer Surveillance Consortium (BCSC), Sickles et al. 2005 [20]) and one from Denmark [21]. In Germany, no documented results exist for diagnostic breast imaging in private practice. Even the oncological documentation in cancer registries is still incomplete. Thus, it can be presumed that in spite of the widespread use of mammography the diagnostic expertise may be quite different. Hence, it was unavoidable to introduce structural and procedural changes in the existent health care system to improve this situation. Since there are no realistic arguments for a different quality of screening and diagnostic mammography, the quality requirements of the European Guidelines for Quality Assurance and Mammographic Screening 2001 have been used for QuaMaDi (with the exception of those quality requirements which are only valid for population-based screening).

The first measures that were taken concerned quality assurance of mammographic technique on all equipments by a medical physicist and a specific training of all involved technologists. The core of every project concerning early detection of breast cancer must be mammography. Double reading increases the sensitivity, and third reading performed by experts increases the specificity and reliability. Within the project, the number of suspicious findings has increased by $40 \%$. The first reader recommended assessment in $4.3 \%$ of cases. After the second reading, this proportion rose to $7.4 \%$. After the third (expert) reading (including dissenting cases of double reading), $6.3 \%$ of the patients were recalled for further assessment. A recall rate of only $6.3 \%$ of cases after the third reading is remarkably low for a diagnostic cohort. In the British National Health Service Screening Programme, a recall rate of $5.8 \%$ has been reported. In The Netherlands, the recall rate is $1.4 \%$ after the first round of screening [16]. However, this low recall rate is associated with a very high rate of $52 \%$ interval carcinomas [11].

In our project, the biopsy rate was 16.2/1,000 examinations. $90 \%$ of these were minimal invasive percutaneous interventions. Thus, a further quality indicator of the S3 guideline 'Early Detection of Breast Cancer' [22] has been achieved, since more than $90 \%$ of all breast cancers could be confirmed histologically before surgery.

In the reference center, $42.9 \%$ of all percutaneous histological assessments yielded malignancy, $57.1 \%$ a benign result. In these cases, surgical biopsy could be avoided. This percentage is somewhat higher than that found by Sickles et al. [20] within the BCSC diagnostic cohort $(39.5 \%)$ and only slightly smaller than that reported by the Finnish Screening Program (48.7\%) [19].

The cancer detection rate in the QuaMaDi project was 10.3 carcinomas/1,000 examinations. After the start of QuaMaDi, the detection rate of breast cancer increased 
by nearly $10 \%$ in the pilot region, whereas it remained unchanged in the other regions of Schleswig-Holstein. Similar effects have been reported with the implementation of screening programs. Besides this increase of population-related incidence within the short project time, it should be noted that the percentage of early lesion stages has increased among the detected cancers, while the number of T2 lesions has decreased simultaneously.

The results reported here underline the importance of a well-functioning and completely documented cancer registry. The QuaMaDi results could never have been assessed correctly without accurate documentation of the situation before the project started. A further conclusion can be drawn from these results: Since, on the one hand, diagnostic mammography in our decentralized health care systems offers so many opportunities for improvement [fig. 3] and, on the other hand, despite an installed screening program more than $75 \%$ of all carcinomas may occur outside the screening program, it cannot be tolerated that mammography is offered in 2 systems with highly differing standards. An adequate decrease of breast cancer mortality can only be achieved by adequate quality control by a well-structured and fully documented prevention in both systems - the system of screening mammography and the system of diagnostic mammography.

\section{References}

1 Tabar L, Yen MF, Vitak B, Chen HH, Smith RA, Duffy SW: Mammography service screening and mortality in breast cancer patients: 20-year followup before and after introduction of screening. Lancet 2003;361:1405-1410.

- 2 Nystrom L, Andersson I, Bjurstam N, Frisell J, Nordenskjold B, Rutqvist LE: Long-term effects of mammography screening: updated overview of the Swedish randomised trials. Lancet 2002;359:909-919.

3 Duffy S W, Tabór L, Cen TH: Reduction in breast cancer mortality from organized service screening with mammogarphy: 1 . Further confirmation with extended data. Cancer Epidemiol Biomarkers Prev 2006;15:45-51.

4 European Reference Organisation for Quality Assured Breast Screening and Diagnostic Services (EUREF): European Guidelines for Quality Assurance in Mammography Screening. European Commission, Luxembourg, 2001.

5 European Reference Organisation for Quality Assured Breast Screening and Diagnostic Services (EUREF): European Guidelines for Quality Assurance in Mammography Screening and Diagnosis. European Commission, Luxembourg, 2006.

6 Parkin DM, Whelan SL, Ferlay J, Storm H: Cancer Incidence in Five Continents, Volumes I-VIII. Lyon, IARC Scientific Publication, 2005.

7 Katalinic A, Bartel C, Raspe H, Schreer I: Beyond mammography screening: quality assurance in breast cancer diagnosis (The QuaMaDi Project). Br J Cancer 2007;96:157-161.

8 American College of Radiology (ACR): Breast Imaging Reporting and Data System, Breast Imaging Atlas. American College of Radiology: Reston, VA, USA, 2003
9 Katalinic A, Waldmann A: Evaluation des Modelvorhabens Qualitätsgesicherte Mammadiagnostik. Schriftenreihe des Instituts für Krebsepidemiologie, Heft 3, Lübeck, 2006.

10 Ciatto S, Ambrogetti D, Bonardi R, Catarzi S, Risso G, Rosselli DT, Mantellini P: Second reading of screening mammograms increases cancer detection and recall rates. Results in the Florence screening programme. J Med Screen 2005;12:103106.

11 Fracheboud J, de Koning HJ, Beemsterboer PM, Boer R, Verbeek AL, Hendriks JH, van Ineveld $\mathrm{BM}$, Broeders MJ, de Bruyn AE, van der Maas PJ: Interval cancers in the Dutch breast cancer screening programme. Br J Cancer 1999;81:912-917.

12 Fracheboud J, de Koning HJ, Boer R, Groenewoud JH, Verbeek AL, Broeders MJ, van Ineveld BM, Hendriks JH, de Bruyn AE, Holland R, van der Maas PJ: Nationwide breast cancer screening programme fully implemented in The Netherlands. Breast 2001;10:6-11.

13 Hackshaw A: EUSOMA review of mammography screening. Ann Oncol 2003;14:1193-1195.

14 Klabunde C, Bouchard F, Taplin S, Scharpantgen A, Ballard-Barbash R: Quality assurance for screening mammography: an international comparison. J Epidemiol Community Health 2001;55:204212.

15 Klabunde CN, Sancho-Garnier H, Taplin S, Thoresen S, Ohuchi N, Ballard-Barbash R: Quality assurance in follow-up and initial treatment for screening mammography programs in 22 countries. Int J Qual Health Care 2002;14:449-461.

16 NHS Cancer Screening Programmes: Annual Review 2004. Sheffield, 2005.
17 Verbeek AL, Broeders MJ: Evaluation of The Netherlands breast cancer screening programme. Ann Oncol 2003;14:1203-1205.

18 Zahl PH, Strand BH, Maehlen J: Incidence of breast cancer in Norway and Sweden during introduction of nationwide screening: prospective cohort study. BMJ 2004;328:921-924.

19 Sarkeala T, Anttila A, Forsman H, Luostarinen T, Saarenmaa I, Hakama M: Process indicators from ten centres in the Finnish breast cancer screening programme from 1991 to 2000. Eur J Cancer 2004; 40:2116-2125.

20 Sickles EA, Miglioretti DL, Ballard-Barbash R, Geller BM, Leung JW, Rosenberg RD, SmithBindman R, Yankaskas BC: Performance benchmarks for diagnostic mammography. Radiology 2005;235:775-790.

21 Jensen A, Vejborg I, Severinsen N, Nielsen S, Rank F, Mikkelsen GJ, Hilden J, Vistisen D, Dyreborg U, Lynge E: Performance of clinical mammography: a nationwide study from Denmark. Int J Cancer 2006;119:183-191.

22 Albert US, Schulz KD: Short version of the guideline: early detection of breast cancer in Germany. An evidence-, consensus-, and outcome-based guideline according to the German Association of the Scientific Medical Societies (AWMF) and the German Agency for Quality in Medicine (AeZQ). J Cancer Res Clin Oncol 2004;130:527-536. 